\title{
0372 CREATION AND EARLY DEVELOPMENT OF AN INJURY OBSERVATORY FOR BRITAIN AND IRELAND (IOBI)
}

D Stone*, R A Lyons, S Turner, Z Quigg, S Barron, M A Bellis, P Brown, C Fischbacher, K Hughes, G Kirkwood, E Lumsden, A Pollock, J Shepherd, W Slater, E Towner, J Verne Correspondence: Paediatric Epidemiology and Community Health (PEACH) Unit, University of Glasgow, Yorkhill Hospital, Glasgow, G3 8SJ, UK

\subsection{6/ip.2010.029215.372}

Objectives The Injury Observatory for Britain and Ireland (IOBI) is an innovative collaboration between the Association of Public Health Observatories and several academic institutions in the four UK home countries and Ireland. Its purpose is to support injury prevention practitioners by making relevant information and tools available through one website.

Methods IOBI emerged from a series of informal meetings of interested professionals in 2004-2005. Being a virtual organisation, IOBI has neither a base nor core funding though many of the constituent organisations receive funding from central or devolved government agencies. The IOBI website http://www. injuryobservatory.net was established in 2007. It enables access to a range of material including injury data across regions and countries, guidance on interpretating injury data, systematic reviews of injury prevention and government strategies on injury prevention. In 2008 we launched an e-newsletter, Injury Prevention News, and added new resources to the website, including an analysis of injury mortality by country and region. Results Key recent achievements include: organisation of the second Injury Prevention Conference for the UK and Ireland in 2009 a comparative analysis of injury hospitalisations to complement mortality data advising on pilots to collect enhanced emergency department data in the UK performing a survey of readers views on Injury Prevention News.

Conclusions Our experience with IOBI demonstrates the need for a forum for injury prevention collaboration in the British Isles. Its success will ultimately be judged by the extent to which it stimulates an increase in injury prevention practice and research. 